\title{
Sílica ativa e cinza do bagaço de cana-de-açúcar: Resíduos que podem suplementar ou substituir o cimento Portland
}

Silica Fume and sugar cane bagasse ash: Wastes that may supplement or replace

\author{
Portland cement
}

Humo de sílice y ceniza del bagazo de caña de azúcar: Residuos que pueden suplementar o sustituir el cemento Portland

Rodrigo Garozi da Silva

Engenheiro Civil, UNESP, Brasil garozirodrigo@gmail.com

Marcelo Bortoletto

Engenheiro Civil, UNESP, Brasil marcelobortoletto05@gmail.com

Jéssica Gomes de Almeida

Engenheira Civil, UNESP, Brasil jejealmeidinha@gmail.com 
Nos dias atuais, o uso de materiais residuais como substituição parcial ao cimento Portland tem se tornado crescente, pelos benefícios que o mesmo proporciona, como o aumento da resistência mecânica e durabilidade em concretos e argamassas, além de colaborar na redução da emissão de gás carbônico que é gerado na produção do clínquer do cimento Portland e ao fato de dar-se uma destinação correta a esses materiais residuais com potencial poluidor. Este artigo é uma revisão da literatura que busca apresentar e discutir as principais características de dois materiais pozolânicos, que podem ser muito eficientes como substituição ao cimento Portland: A sílica ativa e a cinza do bagaço de cana-de-açúcar. De acordo com vários autores esses materiais apresentam bons resultados como substitutos parciais ao cimento Portland, além dos benefícios ambientais que essa substituição pode gerar. $\mathrm{Na}$ literatura, vários ensaios são realizados, buscando sempre avaliar seu potencial e eficácia como material substituto. Concluiu-se então que esses materiais possuem grande potencial e podem substituir parcialmente o cimento em concretos e argamassas desde que observados suas potencialidades de utilização.

PALAVRAS-CHAVE: Emissão de dióxido de carbono. Sílica ativa. Cinza do bagaço de cana-de-açúcar.

\section{ABSTRACT}

Nowadays, the use of waste materials as a partial replacement for Portland cement has been increasing due to its benefits such as increased mechanical strength and durability in concretes and mortars, as well as collaborating to reduce the emission of carbon dioxide which is generated in the production of Portland cement clinker and the fact of giving a correct destination of these waste materials with polluting potential. This paper is a review of the literature that seeks to present and discuss the main characteristics of two pozzolanic materials, which can be very efficient as a replacement for Portland cement: Silica Fume and sugar cane bagasse ash. According to several authors, these materials present good results as partial substitutes for Portland cement, besides the environmental benefits that this substitution can generate. In the literature, several tests are performed, always seeking to evaluate its potential and effectiveness as substitute material. It was concluded that these materials have great potential and may partially replace the cement in concretes and mortars as long as observe its potentialities of use.

KEYWORDS: Emission of carbon dioxide. Silica Fume. Sugar cane bagasse ash.

\section{RESUMEN}

En los días actuales, el uso de materiales residuales como sustitución parcial al cemento Portland se ha vuelto creciente, por los beneficios que el mismo proporciona, como el aumento de la resistencia mecánica y durabilidad en hormigón y morteros, además de colaborar en la reducción de la emisión de gas carbónico Que es generado en la producción del clinker del cemento Portland y al hecho de dar un destino correcto a esos materiales residuales con potencial contaminante. Este artículo es una revisión de la literatura que busca presentar y discutir las principales características de dos materiales pozolánicos, que pueden ser muy eficientes como sustitución al cemento Portland: La humo de sílice y la ceniza del bagazo de caña de azúcar. De acuerdo con varios autores estos materiales presentan buenos resultados como sustitutos parciales al cemento Portland, además de los beneficios ambientales que esa sustitución puede generar. En la literatura, varios ensayos se realizan, buscando siempre evaluar su potencial y eficacia como material sustituto. Se concluyó entonces que esos materiales poseen gran potencial y pueden sustituir parcialmente el cemento en hormigones y morteros desde que se observan sus potencialidades de utilización.

PALABRAS CLAVE: Emisiones de dióxido de carbono. Humo de sílice. Ceniza del bagazo de caña de azúcar 


\section{INTRODUÇÃO}

Com a evolução da humanidade cada vez mais se tornou importante ao ser humano construir para suprir suas necessidades básicas. A evolução dos métodos e materiais de construção, portanto, se tornou inevitável, ao passo que até os dias atuais buscam-se maneiras de aperfeiçoamento para novas construções sempre de maneira sustentável.

Em se tratando de materiais de construção civil, principalmente no Brasil, o mais conhecido é o Cimento Portland, por possuir várias particularidades que o fazem ser o principal material de construção atualmente, amplamente utilizado para a fabricação de concretos estruturais e argamassas para os mais variados fins de aplicação em obras. Porém, existem outros materiais que podem ser adicionados ao cimento ou até substituí-lo, parcial ou totalmente, sem causar prejuízo e muitas vezes melhorando suas propriedades, como é o caso dos materiais com atividade pozolânica.

O presente trabalho tem por objetivo comentar brevemente acerca dos materiais pozolânicos, através de uma revisão da literatura abordando sobre suas principais características e discorrendo os aspectos mais importantes de dois materiais que são resíduos industriais com atividade pozolânica: a sílica ativa e a cinza do bagaço de cana-de-açúcar, com o intuito de aprofundar o conhecimento em materiais de construção civil.

\section{METODOLOGIA EXPLORATÓRIA}

\subsection{Cimento Portland}

O cimento Portland é um aglomerante hidráulico constituído através da mistura sintética de silicato de cálcio obtida a partir da moagem do clínquer e posterior adição de sulfato de cálcio. De acordo com Mehta e Monteiro (2008) o clínquer é uma mistura constituída por compostos a uma elevada temperatura, sendo eles o óxido de cálcio e sílica, alumina e o óxido de ferro. Suas partículas têm dimensões de ordem de 1 a $50 \mu \mathrm{m}$.

A figura 1 mostra como ocorre a queima dos compostos e seus respectivos produtos para a obtenção do clínquer de acordo com Jackson (1998).

Durante o processo de fabricação do cimento Portland, ocorre a emissão de $\mathrm{CO}_{2}$, a emissão ocorre devido ao aquecimento da rocha calcária $\left(\mathrm{CaCO}_{3} \rightarrow \mathrm{CaO}+\mathrm{CO}_{2}\right)$ para a obtenção do óxido de cálcio. Sua produção representa cerca de 5 a $8 \%$ das emissões de $\mathrm{CO}_{2}$ no mundo, e para produzir uma tonelada de cimento Portland são necessárias 2,8 toneladas de matériasprimas. (MORAES et al., 2015) Com o intuito de reduzir essas emissões algumas alternativas estão sendo utilizadas. Uma alternativa é a substituição do clínquer do cimento Portland, por adições de materiais residuais, estes também podem atuar como materiais cimentícios, por exemplo, escórias de alto forno e pozolanas. (FAIRBAIRN et al., 2010) 


\section{ANAP Brasil \\ ISSN 1984-3240 \\ v. 10, n. 21}

\section{REVISTA CIENTIFICA 2017}

FIGURA 1 - Reações que ocorrem durante a queima da matéria-prima para obtenção do clínquer

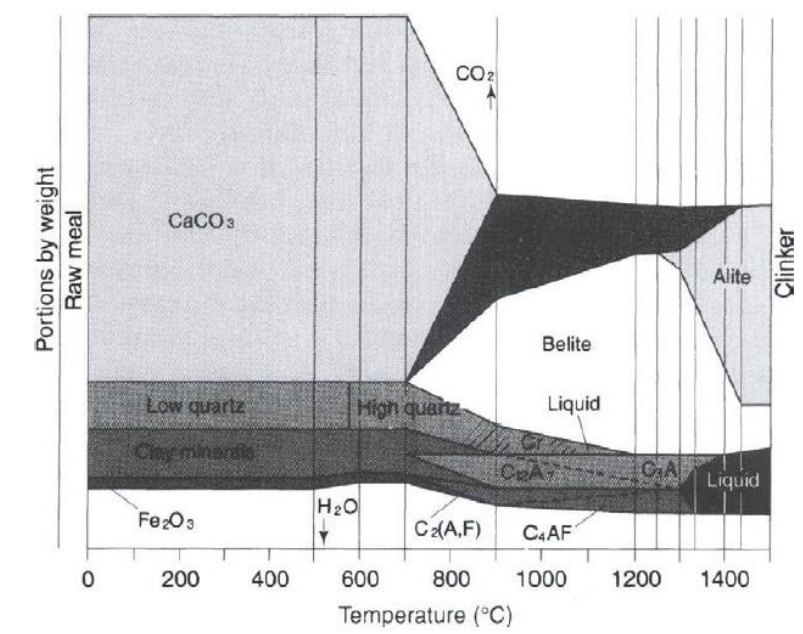

Fonte: JACKSON, 1998.

\subsection{Materiais pozolânicos}

Durante a evolução da humanidade em seus processos construtivos, descobriu-se que os materiais pozolânicos eram excelentes materiais para fabricação de pastas ligantes tanto em termos de resistência como em relação a sua durabilidade em ambientes úmidos e agressivos. Segundo a norma NBR 12653/2014, pozolanas são materiais silicosos ou silicoaluminosos que, por si sós, possuem pouca ou nenhuma atividade aglomerante, mas que, quando finamente divididos e na presença de água, reagem com o hidróxido de cálcio à temperatura ambiente para formar compostos com propriedades aglomerantes.

A norma NBR 12653/2014 ainda subdivide as pozolanas em dois tipos: as pozolanas naturais e artificiais. As pozolanas naturais são de origem vulcânica, de caráter petrográfico ácido ou de origem sedimentar com atividade pozolânica, não necessitando de tratamento térmico. As pozolanas artificiais são materiais provenientes de tratamento térmico ou subprodutos industriais com atividade pozolânica.

De acordo com Jackson (1998) os materiais pozolânicos devem conter predominantemente $\mathrm{SiO}_{2}$ e $\mathrm{Al}_{2} \mathrm{O}_{3}$ em estado reativo, para reagir com o hidróxido de cálcio na presença de água e formar compostos cimentantes, como acontece nos cimentos hidráulicos. Esses dois componentes são imprescindíveis para que aconteça a reação química de formação de componentes de resistência (C-S-H), tanto que a norma NBR 12653/2014 prevê quantidades mínimas de $\mathrm{SiO}_{2}+\mathrm{AlO}_{2}+\mathrm{Fe}_{2} \mathrm{O}_{3}$, para os materiais pozolânicos. Para que o $\mathrm{SiO}_{2}$ e $\mathrm{Al}_{2} \mathrm{O}_{3}$ consigam reagir e formar compostos de resistência estes devem se apresentar em estado amorfo. Se esses materiais se apresentarem em fases cristalinas, não reagem com o hidróxido de cálcio sendo assim um material inerte.

Quando a pozolana é adicionada ao cimento Portland, ela reage com o hidróxido de cálcio formado durante a hidratação dos silicatos do clínquer (em pastas de cimento endurecidas têm-se aproximadamente 20 a $25 \%$ de hidróxido de cálcio). Como resultado, o teor de 


\section{ANAP Brasil}

ISSN 1984-3240

v. 10, n. 21

\section{REVISTA CIENTIFICA 2017}

hidróxido de cálcio nas pastas de cimento contendo pozolana é sempre menor, em relação às pastas de cimento Portland sem a adição de pozolana. (MASSAZZA, 1993)

\subsubsection{Sílica Ativa}

De acordo com a norma $\mathrm{ACl} 234 \mathrm{R}-06$, sílica ativa é um material muito fino não cristalino, produzida em fornos a arco elétrico como um subproduto da produção de silício elementar ou de ligas contendo silício. Tem um teor muito elevado de dióxido de silício amorfo e consiste em partículas esféricas pequenas, com um diâmetro de 0,1 a 0,2 $\mu \mathrm{m}$. Muitas vezes, várias esferas individuais podem ser fundidas juntas com objetivo de formar pequenos aglomerados. Também é conhecida como "microsílica".

Desde 1950 a sílica ativa começou a ser testada na Noruega, e percebeu-se que esse material adicionado ao concreto contribuía para a resistência e durabilidade, porém na época sua produção não era viável, pois não havia métodos eficientes para reter as partículas ultrafinas da sílica nos fornos. Até que em 1970 o governo norueguês fez severas exigências ambientais para empresas, com o intuito de reduzir a emissão de poluentes, melhorando assim a tecnologia e mecanismos de filtragem. Com isso a obtenção de sílica começou a ser vasta, o que incentivou mais pesquisas nesse campo, fazendo atualmente a sílica ser muito utilizada como um material alternativo na construção civil. (FIDJESTOL; LEWIS, 1998)

A sílica ativa é obtida a partir da redução do quartzo à alta temperatura em fornos a arcos elétricos, onde os principais produtos são o silício ou ligas contendo silício, como já citado anteriormente. O quartzo é aquecido a uma temperatura de $2000^{\circ} \mathrm{C}$. Carvão ou lascas de madeira são adicionados para remover o oxigênio. A liga é coletada no fundo do forno, e à medida que o quartzo vai se transformando em liga, libera-se vapor de SiO (Óxido de Silício). Nas partes superiores do forno o óxido de silício se condensa em microesferas de sílica amorfa $\left(\mathrm{SiO}_{2}\right)$ e na sequência estas são extraídas do forno através de ventiladores, onde ocorre a remoção das partículas grosseiras de madeira ou carbono através de filtros grosseiros, para depois a sílica ser conduzida por uma série de filtros especiais. (FIDJESTOL; LEWIS, 1998)

Os materiais formados na fabricação do silício elementar contêm cerca de 90 a $98 \%$ de $\mathrm{SiO}_{2}$ (dióxido de silício), todavia ao material formado a partir da fabricação de ligas de silício a porcentagem de $\mathrm{SiO}_{2}$ é de cerca de 86 a 90\%, este último é o mais usual, quando utilizado para produzir concretos e argamassas com elevada durabilidade e resistência mecânica. (TAYLOR, 1990)

A figura 2 mostra o funcionamento do processo de obtenção da sílica de acordo com Fidjestol e Lewis (1998). 


\section{ANAP Brasil \\ ISSN 1984-3240 \\ v. 10, n. 21}

\section{REVISTA CIENTIFICA 2017}

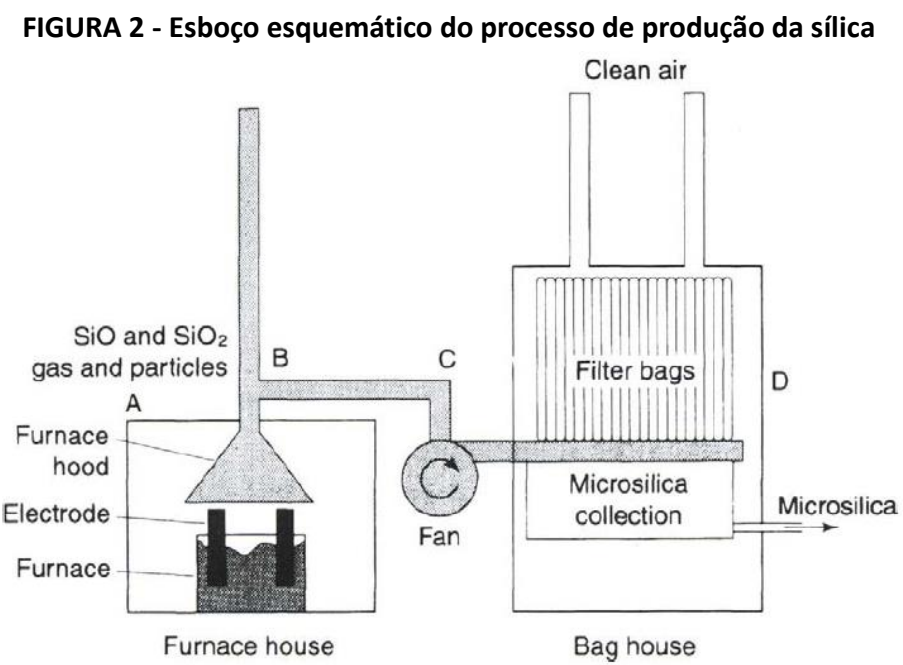

Fonte: FIDJESTOL E LEWIS, 1998.

No concreto fresco a sílica ativa auxilia em vários aspectos benéficos. Com sua adição em substituição a parte do cimento, reduz-se notadamente a segregação, uma vez que as partículas finas ocupam pequenos vazios que há no concreto, impedindo a subida da água (que é mais leve que os outros componentes), por canais capilares. Esses finos auxiliam no preenchimento desses capilares, dando também maior coesão na mistura. Isso também é benéfico para o concreto endurecido, uma vez que com a presença dos finos da sílica auxiliando a preencher os vazios que, sem essa adição seriam preenchidos de água livre, aumenta-se a durabilidade do concreto, pois essa água seria evaporada, havendo espaço para infiltração de águas e agentes agressivos pelos capilares vazios. (ACl 234R-06)

Além disso, têm-se também as modificações químicas que a sílica provoca quando é adicionada ao concreto por exemplo. A principal é devido ao fato da sílica ser um material com alta reatividade pozolânica, reagindo assim com o hidróxido de cálcio produzido pela hidratação do cimento. De acordo com a ACl 234R-06 descobriu-se que em uma substituição de $20 \%$ em volume de sílica por cimento, em uma pasta, não foi detectado $\mathrm{CaOH}_{2}$ depois de 91 dias de cura a $23{ }^{\circ} \mathrm{C}$, enquanto que para uma substituição de $10 \%$, foi detectado $50 \%$ de $\mathrm{CaOH}_{2}$, para a mesma idade.

\subsubsection{Cinza do bagaço de cana-de-açúcar}

O uso de cinzas de bagaço de cana-de-açúcar como adição ao cimento Portland, têm-se tornado uma alternativa interessante, especialmente em países onde a produção de materiais utilizados como adição ao cimento Portland é pequena, como é o caso das cinzas volantes, escórias de alto forno e pozolanas naturais. Há estudos que relatam que o uso da cinca do bagaço de cana-de-açúcar como adição, tem efeitos positivos em questão à reologia, durabilidade e propriedades mecânicas do concreto, e colabora na redução de emissão de dióxido de carbono na atmosfera, por conta da substituição parcial do cimento Portland. (CORDEIRO; KURTIS, 2017) 
A adição de cinzas em concretos é cada vez mais frequente devido à alta reatividade das cinzas com a cal (hidróxido de cálcio). Os resíduos de cana-de-açúcar adquirem uma atividade pozolânica adequada, quando calcinadas a temperaturas superiores a 600 oC (MORALES et al.,2009).

De acordo com Cordeiro, Toledo Filho e Fairbairn (2009), a produção da cinza do bagaço no Brasil é de mais de 2,5 milhões de toneladas por ano, esse valor corresponde a cerca de $6 \%$ da produção de cimento no país. A cinza do bagaço de cana-de-açúcar é gerada como subproduto da queima do bagaço de cana-de-açúcar. Nas usinas, o bagaço puro é queimado nas caldeiras, que geram cerca de $0,3 \%$ da massa total de cana-de-açúcar processada.

Em geral o principal produto obtido da queima do bagaço é dióxido de silício, este pode ser encontrado em estado amorfo, ou em estado de polimorfos cristalinos. Se a queima do bagaço for adequada é possível obter a sílica em estado amorfo. (CORDEIRO; KURTIS, 2017)

Ainda de acordo com Cordeiro e Kurtis (2017), para um melhor aproveitamento da reatividade pozolânica da cinza do bagaço de cana-de-açúcar é essencial realizar uma boa moagem nas cinzas, pois desta maneira uma maior parte da cinza pode reagir com o hidróxido de cálcio.

\section{RESULTADOS E DISCUSSÕES EXPLORATÓRIOS}

A seguir serão mostrados alguns resultados de pesquisas e ensaios realizados acerca desses materiais pozolânicos, e discutido a respeito de sua influencia e eficiência como substitutos do cimento Portland.

Normalmente para se avaliar a presença de fases cristalinas nos materiais pozolânicos realizase o ensaio de difração de raios $X$, que pode identificá-las. A figura 3 mostra os resultados obtidos por Tashima et al. (2014) nesse tipo de ensaio, em que foi analisado dois tipos de sílica ativa, uma sílica altamente densificada e uma sílica pouco densificada (DSF-H - DSF-L). No mesmo ensaio foi utilizado outro material para comparação, a cinza da casca de arroz, uma com característica amorfa, e a outra com característica cristalina (RHA-A - RHA-C). Os resultados mostram que grandes picos enfatizam presença de material cristalino e desvios da linha base evidenciam a presença de material amorfo. Nesse caso a sílica ativa aparenta pouca presença de materiais em fases cristalinas.

Para verificar a efetividade pozolânica da sílica ativa são realizados ensaios onde se substitui sílica ativa em pastas de cimento, em que o consumo do hidróxido de cálcio evidencia a reatividade da sílica e consequente eficiência do material como substituto do cimento. De acordo com a ACl 234R-06, a figura 4 mostra a quantidade de hidróxido de cálcio em pastas de cimento com diferentes idades de cura para diferentes quantidades de sílica substituída. É possível analisar que quanto menos cimento tem-se na pasta, menos hidróxido de cálcio é formado, e ao mesmo passo, quanto maior a porcentagem de sílica, mais rápido é o consumo de hidróxido de cálcio. 


\section{ANAP Brasil \\ ISSN 1984-3240 \\ v. 10, n. 21}

\section{REVISTA CIENTIFICA 2017}

FIGURA 3 - Difração de raios X das pozolanas selecionadas. (C- cristobalita, Q- quartzo, T- tridimita, X- sílica)

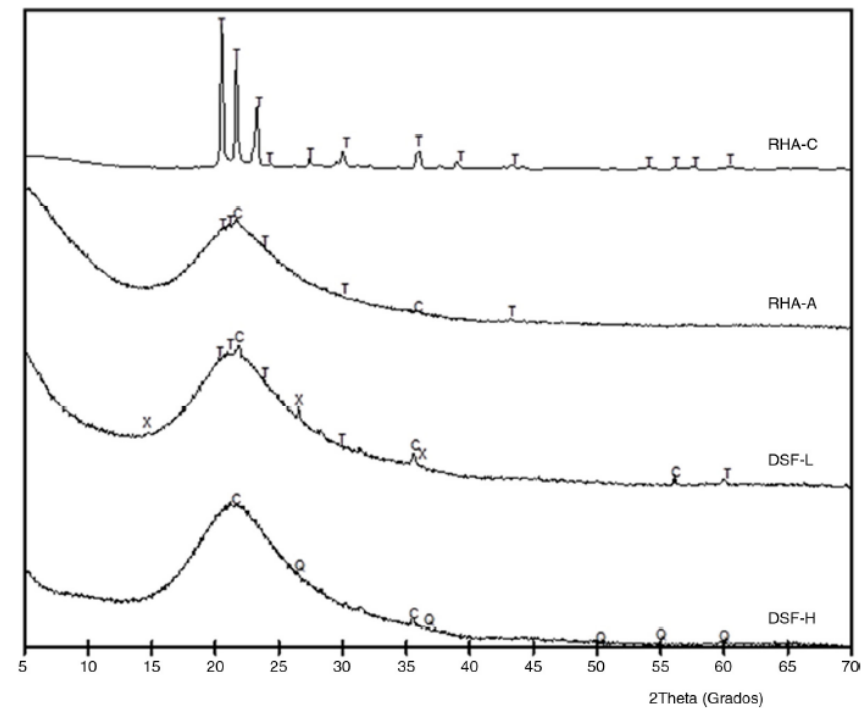

Fonte: TASHIMA ET AL., 2014.

FIGURA 4 - Quantidades de hidróxido de cálcio em pasta de cimento contendo diferentes quantidades de sílica ativa

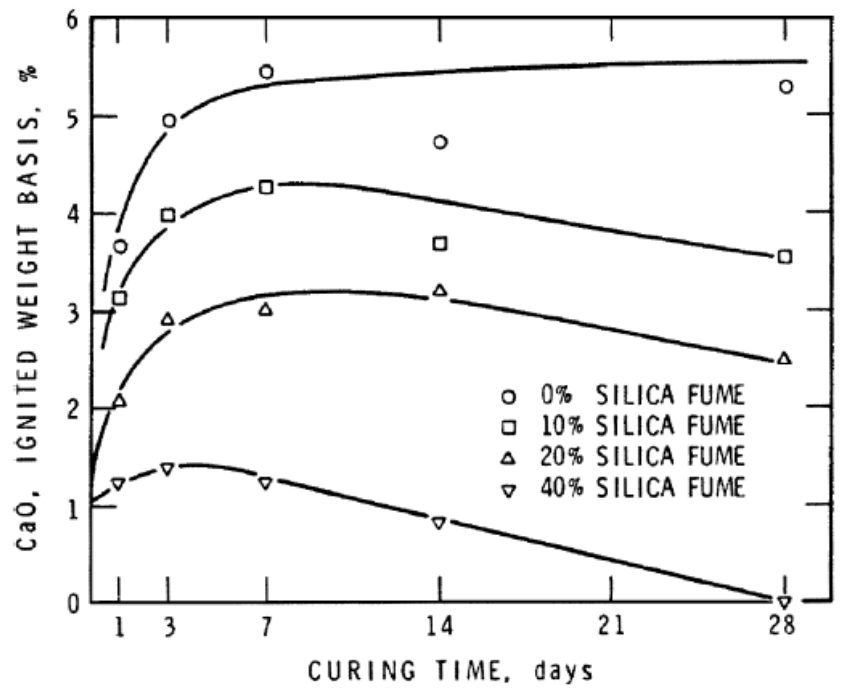

Fonte: ACI 234R-06.

Com o objetivo de confirmar a efetividade pozolânica das cinzas de bagaço de cana-de-açúcar alguns autores realizaram ensaios com o objetivo de avaliar a reatividade de algumas amostras desse material. Cordeiro e Kurtis (2017) mostram em seu trabalho (figura 5) difração de raio X (que evidenciam as fases amorfas e cristalinas) para a cinza do bagaço de cana-de-açúcar (duas amostras em diferentes granulometrias SBCA1 e SBCA4) por eles pesquisada e alguns outros materiais (cinza de casca de arroz - RHA e Quartzo - QTZ). 


\section{REVISTA CIENTIFICA 2017}

FIGURA 5 - Padrões de difração de raios X de RHA, SCBA1, SCBA-4 e QTZ medidos utilizando um difractómetro $X ' P e r t$ Pro (Panalytical, Almelo-Netherlands) operado a $45 \mathrm{kV}$ e $40 \mathrm{~mA}, 10^{\circ}-58^{\circ} 20$ gama, $0,016^{\circ}$ passo tamanho, E 10 s de tempo de contagem

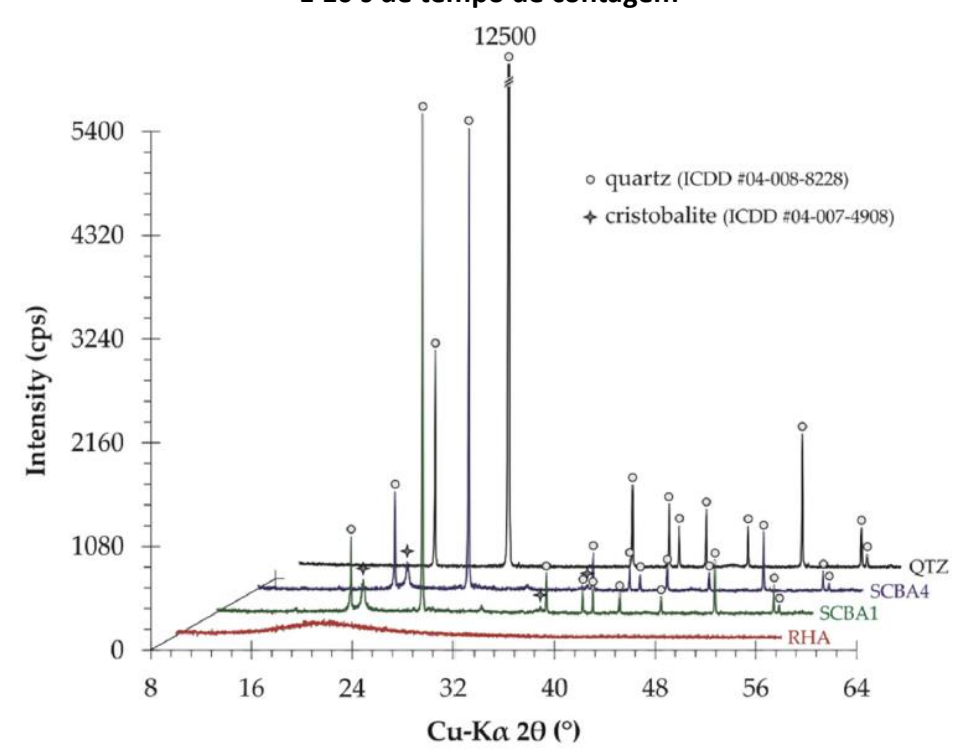

Fonte: CORDEIRO E KURTIS, 2017.

Nota-se neste caso particular que essas amostras de cinza apresentam algumas fases cristalinas, como o quartzo e a cristobalita. Isso não indica a total ineficiência pozolânica do material, que pode também apresentar fases amorfas e essas reagirem com o hidróxido de cálcio.

Ainda de acordo com Cordeiro e Kurtis (2017), para um melhor aproveitamento da reatividade pozolânica da cinza do bagaço de cana-de-açúcar é essencial realizar uma boa moagem nas cinzas, pois desta maneira uma maior parte da cinza pode reagir com o hidróxido de cálcio. Em seus experimentos, os autores comprovaram isso, utilizando um material pozolânico com alta reatividade para controle (neste caso a cinza de casca de arroz), cinza de bagaço de cana-deaçúcar moída em diferentes granulometrias (P-SCBA1, P-SCBA2, P-SCBA3 e P-SCBA4) e quartzo moído finamente (não reativo), misturados à pastas de cimento como adição em $20 \%$ da massa de cimento utilizada, observando seu comportamento em vários aspectos. A figura 6 mostra os resultados obtidos de quantidades de hidróxido de cálcio nas pastas, enquanto a tabela 1 determina algumas características dos materiais utilizados e o índice de atividade de resistência. 


\section{ANAP Brasil \\ ISSN 1984-3240 \\ v. 10, n. 21}

\section{REVISTA CIENTIFICA 2017}

FIGURA 6 - Conteúdo de Portlandita normalizada $(\mathrm{CH})$ para a massa de cimento para todas as pastas

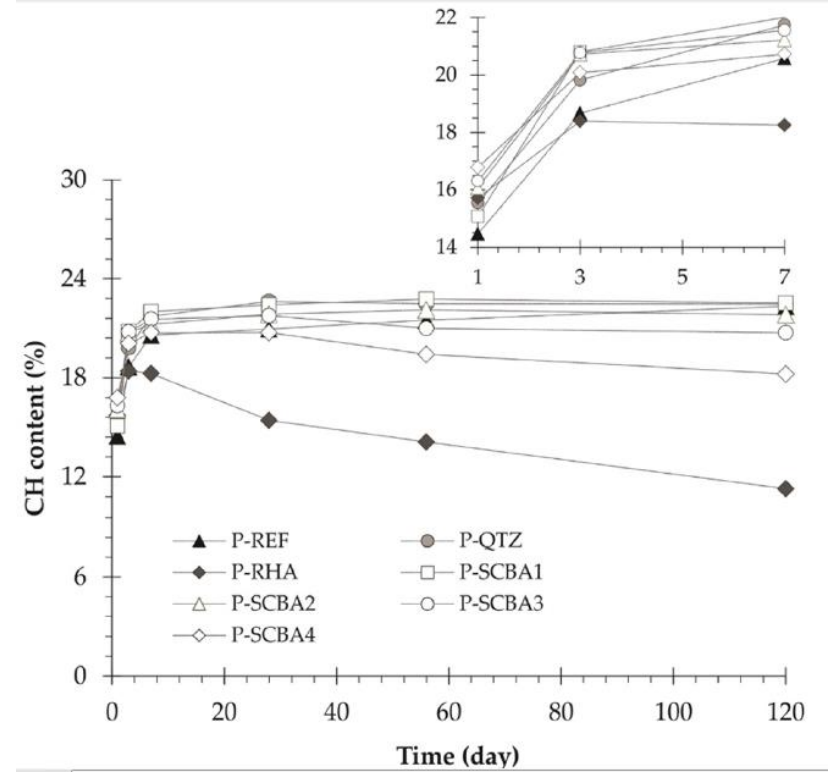

Fonte: CORDEIRO E KURTIS, 2017.

Tabela 1: D50, área de superfície específica através de BET, fração solúvel (os valores de desvio padrão são indicados entre parênteses) e valores de índice de atividade de resistência de todas as adições de minerais

\begin{tabular}{|c|c|c|c|c|c|}
\hline \multirow[b]{2}{*}{ Paste } & \multirow[b]{2}{*}{$D_{50}(\mu \mathrm{m})$} & \multirow{2}{*}{$\begin{array}{c}\text { BET specific } \\
\text { surfasse área } \\
\left(\mathrm{m}^{2} / \mathrm{kg}\right)\end{array}$} & \multirow{2}{*}{$\begin{array}{c}\text { Soluble } \\
\text { fraction } \\
(\%)\end{array}$} & \multicolumn{2}{|c|}{ Strength activity index (\%) } \\
\hline & & & & 7 - day & 28 - day \\
\hline QTZ & 7.8 & 2,770 & $1.2( \pm 0.1)$ & 58 & 67 \\
\hline RHA & 6.2 & 38,650 & $89.7( \pm 1.7)$ & 103 & 118 \\
\hline SCBA 1 & 29.6 & 2,970 & $9.6( \pm 0.3)$ & 61 & 74 \\
\hline SCBA 2 & 14.7 & 4,585 & $10.0( \pm 0.4)$ & 69 & 82 \\
\hline SCBA 3 & 6.8 & 8,240 & $17.3( \pm 0.6)$ & 85 & 99 \\
\hline SCBA 4 & 4.4 & 11,350 & $20.4( \pm 0.7)$ & 92 & 106 \\
\hline
\end{tabular}

Fonte: CORDEIRO E KURTIS, 2017.

Nota-se que o maior consumo de hidróxido de cálcio ocorreu para a amostra com adição de cinza de casca de arroz altamente reativa. Porém, é possível observar que a amostra moída mais finamente (P-SCBA4) consumiu uma quantidade relevante de hidróxido de cálcio, fato que mostra a importância de uma boa moagem desse material. Também é possível notar que a amostra mais refinada apresenta um maior índice de atividade de resistência. 


\section{ANAP Brasil \\ ISSN 1984-3240 \\ v. 10, n. 21}

\section{REVISTA CIENTIFICA 2017}

\section{CONCLUSÕES}

Nota-se que os dois materiais discutidos, podem ser considerados, de acordo com as exigências como materiais pozolânicos e possíveis substitutos do cimento Portland. As principais diferenças percebidas entre eles serão descritas a seguir:

Os processos de obtenção dos compósitos são bastante distintos, porém ambos são materiais residuais que além de não poluírem a natureza com o seu descarte inadequado, podem ajudar a reduzir as emissões de dióxido de carbono que são provenientes da fabricação do cimento Portland, através de sua substituição.

Em relação as propriedades químicas, os dois materiais apresentam principal composição constituída de compósitos sílicos, porém esse silício pode encontrar-se em maior concentração de forma amorfa nas sílicas ativas, esse fato se deve a possibilidade de queimas não controladas do bagaço para a obtenção das cinzas de cana-de-açúcar.

Ambos os materiais, portanto, podem ser usados como adições minerais, desde que sejam observados as potencialidades e efeitos que cada um pode produzir nas argamassas ou concretos, bem como a finalidade que esses serão utilizados, para que se alcance bons resultados buscando sempre a sustentabilidade.

\section{AGRADECIMENTO}

Os autores agradecem ao Professor Doutor Mauro M. Tashima pelo apoio à elaboração do presente artigo.

\section{REFERÊNCIAS BIBLIOGRÁFICAS}

AMERICAN CONCRETE INSTITUTE. ACI 234R-06: Guide for the Use of Silica Fume in Concrete. Indianapolis: Aci, 2006.

ASSOCIAÇÃO BRASILEIRA DE NORMAS TÉCNICAS - ABNT. NBR 12653: Materiais pozolânicos. Rio de Janeiro, 2014.

BLEZARD, Robert G.. The History of Calcareous Cements. In: HEWLETT, Peter C. (Ed.). Lea's Chemistry of Cement and Concrete. 4. ed. Burlington: Elsevier, 1998. Cap. 1. p. 1-23.

COHEN, Menashi D.; OLEK, Jan; DOLCH, William L.. Mechanism of plastic shrinkage cracking in portland cement and portland cement-silica fume paste and mortar. Cement And Concrete Research, [s.l.], v. 20, n. 1, p.103-119, jan. 1990. Elsevier BV. http://dx.doi.org/10.1016/0008-8846(90)90121-d.

CORDEIRO, G.c.; TOLEDO FILHO, R.d.; FAIRBAIRN, E.m.r.. Effect of calcination temperature on the pozzolanic activity of sugar cane bagasse ash. Construction And Building Materials, [s.I.], v. 23, n. 10, p.3301-3303, out. 2009. Elsevier BV. http://dx.doi.org/10.1016/j.conbuildmat.2009.02.013.

CORDEIRO, Guilherme C.; KURTIS, Kimberly E.. Effect of mechanical processing on sugar cane bagasse ash pozzolanicity. Cement And Concrete Research, [s.l.], v. 97, p.41-49, jul. 2017. Elsevier BV. http://dx.doi.org/10.1016/j.cemconres.2017.03.008.

FAIRBAIRN, Eduardo M.r. et al. Cement replacement by sugar cane bagasse ash: CO2 emissions reduction and potential for carbon credits. Journal Of Environmental Management, [s.I.], v. 91, n. 9, p.1864-1871, set. 2010. Elsevier BV. http://dx.doi.org/10.1016/j.jenvman.2010.04.008. 
FARIA, E. F. de. Predição da exotermia da reação de hidratação do concreto através de modelo termo-químico e modelo de dados. Tese (Doutorado). Rio de Janeiro, 2004. 130 p. Universidade Federal do Rio de Janeiro, COPPE.

FIDJESTOL, Per; LEWIS, Robert. Microsilica as an Addition. In: HEWLETT, Peter (Ed.). Lea's of cement and concrete. 4. ed. London: Elsevier, 1998. Cap. 12. p. 679-712.

HOLLAND, Terence C.. Silica Fume User's Manual. Lovettsville: Silica Fume Association, 2005.

JACKSON, Peter J.. Portland Cement: Classification and Manufacture. In: HEWLETT, Peter C. (Ed.). Lea's Chemistry of Cement and Concrete. 4. ed. Burlington: Elsevier, 1998. Cap. 2. p. 25-94.

KIHARA, Y. et al. A microscopia do clínquer Portland e seus benefícios tecnológicos. In: CONGRESSO BRASILEIRO DE CIMENTO, 2, 1990, São Paulo. Anais. São Paulo: Associação Brasileira de Cimento Portland, 1990.

MASSAZZA, F. Pozzolanic Cements. Cement \& Concrete Composites, v.15, p.185-214, 1993.

MASSAZZA, Franco. Pozzolana and Pozzolanic Cements. In: HEWLETT, Peter (Ed.). Lea's of cement and concrete. 4. ed. London: Elsevier, 1998. Cap. 10. p. 471-635.

MEHTA, P. Kumar; MONTEIRO, Paulo J. M.. Concreto: Microestrutura, Propriedades e Materiais. 3. ed. São Paulo: Ibracon, 2008. $674 \mathrm{p}$.

MORAES, J.c.b. et al. Assessment of sugar cane straw ash (SCSA) as pozzolanic material in blended Portland cement: Microstructural characterization of pastes and mechanical strength of mortars. Construction And Building Materials, [s.I.], v. 94, p.670-677, set. 2015. Elsevier BV. http://dx.doi.org/10.1016/j.conbuildmat.2015.07.108.

MORALES, E.v. et al. Effects of calcining conditions on the microstructure of sugar cane waste ashes (SCWA): Influence in the pozzolanic activation. Cement And Concrete Composites, [s.I.], v. 31, n. 1, p.22-28, jan. 2009. Elsevier BV. http://dx.doi.org/10.1016/j.cemconcomp.2008.10.004.

ODLER, I. Hydration, setting and hardening of Portland cement: In: HEWLETT, Peter (Ed.). Lea's Chemistry of cement and concrete. 4. ed. London: Elsevier, 1998. Cap. 6. p 241-297.

PANDEY, Ashok et al. Biotechnological potential of agro-industrial residues. I: sugarcane bagasse. Bioresource Technology, [s.I.], v. 74, n. 1, p.69-80, ago. 2000. Elsevier BV. http://dx.doi.org/10.1016/s0960-8524(99)00142-x.

PEDRO, D.; BRITO, J. de; EVANGELISTA, L.. Evaluation of high-performance concrete with recycled aggregates: Use of densified silica fume as cement replacement. Construction And Building Materials, [s.l.], v. 147, p.803-814, ago. 2017. Elsevier BV. http://dx.doi.org/10.1016/j.conbuildmat.2017.05.007.

ROJAS, Moisés Frías; CABRERA, Joseph. The effect of temperature on the hydration rate and stability of the hydration phases of metakaolin-lime-water systems. Cement And Concrete Research, [s.l.], v. 32, n. 1, p.133-138, jan. 2002. Elsevier BV. http://dx.doi.org/10.1016/s0008-8846(01)00642-1.

TASHIMA, M. M. et al. New method to assess the pozzolanic reactivity of mineral admixtures by means of $\mathrm{pH}$ and electrical conductivity measurements in lime: pozzolan suspensions. Materiales de Construcción, [s.l.], v. 64, n. 316, p.32-44, 24 set. 2014. Departmento de Publicaciones del CSIC. http://dx.doi.org/10.3989/mc.2014.00914.

TAYLOR, H. F. W. Cement Chemistry. London: Academic Press, 1990. 475p.

YAJUN, Ji; CAHYADI, Jong Herman. Effects of densified silica fume on microstructure and compressive strength of blended cement pastes. Cement And Concrete Research, [s.I.], v. 33, n. 10, p.1543-1548, out. 2003. Elsevier BV. http://dx.doi.org/10.1016/s0008-8846(03)00100-5. 